\title{
Índice de Desempenho da Gestão Ambiental (IDGA) aplicado ao SETOR TÊXTIL: UM ESTUdo EM DUAS LAVANDERIAS INDUSTRIAIS DO AgRESTE PERNAMBUCANO
}

\author{
Fernanda Maria D’Emery Cavalcanti ${ }^{1}$, Marília Regina Costa Castro Lyra ${ }^{2}$, José Antônio Aleixo da Silva ${ }^{3}$
}

\author{
1 Instituto Federal de Pernambuco - IFPE/Campus Recife/Mestrado Profissional em Gestão Ambiental do IFPE \\ 2 Instituto Federal de Pernambuco - IFPE/Campus Recife/ Mestrado Profissional em Gestão Ambiental do IFPE \\ 3 Universidade Federal Rural de Pernambuco/ Mestrado Profissional em Gestão Ambiental do IFPE \\ *Autor correspondente: nandademery2@hotmail.com
}

Recebido em 08 de junho de 2016. Aceito em 20 de dezembro de 2018. Publicado em 31 de julho de 2019.

\begin{abstract}
Resumo - O setor têxtil exige elevado nível de competitividade e atualização das empresas, ao mesmo tempo em que responde a diversos normativos ambientais devido a seu potencial de geração de externalidades negativas. Um dos grandes polos de produtos têxteis no Brasil localiza-se no Agreste pernambucano, com foco na produção de jeans. Há diversos municípios que têm sua economia positivamente influenciada por este mercado. Contudo, existe diversos problemas sociais e ambientais relacionados ao consumo de água, ao descarte inadequado dos efluentes nos cursos d'água e às condições insalubres de trabalho. Diante desta problemática, este artigo tem como objetivo a definição do grau de maturidade da gestão ambiental de empresas do setor têxtil por meio da aplicação do Índice de Desempenho da Gestão Ambiental (IDGA), indicador ambiental desenvolvido no âmbito do Programa de Pós-graduação em Desenvolvimento e Meio Ambiente da Universidade Federal de Pernambuco (PRODEMA). O conhecimento do IDGA das organizações serve como ponto de partida para a identificação de pontos de melhoria em aspectos socioambientais. A metodologia do IDGA foi aplicada em duas lavanderias têxteis do município de Toritama, Pernambuco, e os resultados identificados foram de nível médio nos dois casos, respeitadas as particularidades quanto ao desenvolvimento de cada um dos aspectos analisados.
\end{abstract}

Palavras-chave: Aspectos ambientais. Jeans. Toritama. Desempenho ambiental.

Environmental Performance Index (EPI) applied to the textile sector: a study case of two textile laundries in the countryside of Pernambuco

\begin{abstract}
The textile sector requires a high level of competitiveness and updating of companies, while at the same time responding to various environmental regulations due to its potential to generate negative externalities. One of the great poles of textile products in Brazil is located in the countryside of Pernambuco, with a focus on the production of jeans. There are several counties that have their economy positively influenced by this market. However, there are various social and environmental problems related to the consumption of water, the inadequate disposal of effluents in water courses and unhealthy working conditions. In view of this problem, this article aims to define the degree of maturity of the environmental management of companies in the textile sector through the application of the Environmental Performance Index (EPI), an environmental indicator developed under the Postgraduate Program in Development and Environment of the Federal University of Pernambuco (PRODEMA). Knowing the EPI of organizations serves as a starting point for the identification of improvement points in social and environmental aspects. The methodology of the EPI was applied in two textile laundries of the city of Toritama, Pernambuco, and the results identified were of medium level in both cases, respecting the peculiarities regarding the development of each of the aspects analyzed.
\end{abstract}


KEYwords: Environmental aspects. Jeans. Toritama. Environmental performance.

Índice de Desempeño de la Gestión Ambiental (IDGA) aplicado al SECtor teXtil: un ESTUdio en dos laVANDERÍAS industriales del Agreste pernambucano

Resumen - El sector textil exige un alto nivel de competitividad y actualización de las empresas, a la vez que responde a diversos reglamentos ambientales debido a su potencial de generación de externalidades negativas. Uno de los grandes centros de productos textiles en Brasil se localiza en el Agreste pernambucano, con foco en la producción de jeans. Hay varios municipios que tienen su economía positivamente influenciada por este mercado. Sin embargo, existen diversos problemas sociales y ambientales relacionados con el consumo de agua, el desecho inadecuado de los efluentes en los cursos de agua y a las condiciones insalubres de trabajo. En este sentido, este artículo tiene como objetivo la definición del grado de madurez de la gestión ambiental de empresas del sector textil a través de la aplicación del Índice de Desempeño de la Gestión Ambiental (IDGA), indicador ambiental desarrollado en el ámbito del Programa de Posgrado en Desarrollo y Medio Ambiente de la Universidade Federal de Pernambuco (PRODEMA). El conocimiento del IDGA de las organizaciones sirve como punto de partida para la identificación de puntos de mejora en aspectos socioambientales. La metodología del IDGA fue aplicada en dos lavanderos textiles del municipio de Toritama, Pernambuco, y los resultados identificados fueron de nivel medio en los dos casos, respetando las particularidades en cuanto al desarrollo de cada uno de los aspectos analizados.

Palavras Clave: Aspectos ambientales. Jeans. Toritama. Desempeño ambiental.

\section{INTRODUÇÃO}

O setor têxtil é caracterizado por uma demanda dicotômica quanto à velocidade de atualização e competitividade do mercado em contraponto ao cumprimento de normas ambientais cujas restrições são alinhadas ao seu potencial de geração de externalidades negativas.

Composto de um conjunto de indústrias de fiação (responsável pela produção da principal matéria prima do setor - o tecido) e das indústrias de confecção, o setor têxtil influencia o crescimento econômico de diversos países emergentes, o que também ocorre com o Brasil (Santiago 2011). Segundo ABIT (2014), os dados gerados pela indústria têxtil, em relação a quantitativo de empregos associados, alcançaram no ano de 2013, a marca de 1,7 milhões, representando $16,4 \%$ dos empregos associados à indústria de transformação brasileira. No ranking mundial ocupa o $5^{\circ}$ lugar entre os países produtores de têxteis, possuindo o $4^{\circ}$ maior parque produtivo do setor.

A indústria têxtil brasileira é centrada em diversos polos, cada um deles sendo especialista em determinado tipo de confecção, sendo localizado no agreste do estado de Pernambuco o polo especialista na produção de peças em jeans.

Neste contexto, o setor têxtil exige respostas rápidas quanto as obrigações legais em relação a utilização de recursos naturais e descarte de resíduos e efluentes, o que demanda uma gestão estratégica comprometida com princípios de sustentabilidade.

É percebido, portanto, a incorporação do tripé da sustentabilidade na maioria das empresas, onde o equilíbrio entre o resultado econômico e o capital social e ambiental é respeitado gerando externalidades positivas. $\mathrm{O}$ quantitativo e o refinamento dos estudos acerca do modus operandi vigente da economia mundial têm sido determinantes para a definição de novos padrões de conduta impostos - tanto por meio de leis quanto pelas pressões dos stakeholders - às organizações (Tashizaua e Andrade 2008).

Uma ferramenta importante na mensuração do resultado ambiental apresentado pelas empresas pode ser um indicador de desempenho. Em linhas gerais, indicador é tudo aquilo que indica o progresso em relação a uma determinada meta, que pode ser a melhoria do desempenho ambiental da empresa (Bellen 2005). O Índice de Desenvolvimento da Gestão Ambiental (IDGA), desenvolvido por Barros (2011), representa um indicador 
que mensura o nível de desenvolvimento da gestão ambiental de uma organização, podendo auxiliar na tomada de decisão a respeito de pontos de melhoria e reforço das estratégias ambientais da empresa, tornando-se um potencial aliado na obtenção de certificações ambientais.

Considerando a problemática exposta, este artigo tem como objetivo a definição do grau de maturidade da gestão ambiental de empresas do setor têxtil por meio da aplicação do Índice de Desempenho da Gestão Ambiental (IDGA) - indicador ambiental desenvolvido no âmbito do Programa de Desenvolvimento e Meio Ambiente da Universidade Federal de Pernambuco (PRODEMA/UFPE).

A proposta deste trabalho versa sobre a indústria têxtil do agreste pernambucano, mais especificamente o setor de lavagem, cuja região mais representativa é a de Toritama, onde a produção de jeans é bastante intensa e historicamente pouco fiscalizada, o que dá margem a atividades pouco estruturadas e com alto potencial nocivo ao ambiente natural. Segundo SEBRAE (2004), o polo de confecções pernambucano concentra mais de 60\% dos estabelecimentos industriais do setor, gerando cerca de 120 mil empregos e representando 15\% da produção brasileira. A indústria têxtil tem contribuído para o desenvolvimento da economia de vários municípios, tornando menor o desemprego e ampliando as oportunidades dos empreendedores, além de ter gerado e contribuir para perpetuar a característica de localidade que produz jeans de qualidade a preços competitivos, ou seja, desenvolveuse um aspecto cultural que culmina em festas e incremento do turismo local.

O interesse em larga escala pela implementação do setor têxtil na região do Agreste pernambucano surgiu na década de 70 a partir de um movimento espontâneo de pequenos empreendedores locais. O processo funcionou como uma estratégia de melhoria das carentes condições de vida daquela população, que estava com poucas perspectivas depois da decadência da produção de sapatos de borracha, principal atividade econômica da região até então. Tem-se, portanto, um cenário marcado por diversos empreendimentos informais de cunho familiar, o que dificulta sua fiscalização e facilita práticas não adequadas tanto do ponto de vista social quanto do ambiental, porém, estes mesmos empreendimentos são responsáveis pela saúde econômica de diversos municípios do agreste pernambucano, o que torna qualquer ação no sentido de formalizar e fiscalizar os empreendimentos um tanto delicada (DIEESE 2010).

Apesar disso, roupas, acessórios e todos os produtos gerados pela indústria têxtil são elementos presentes no cotidiano da quase totalidade dos indivíduos e são deveras representativos quando se trata da demarcação de estilo pessoal. De acordo com Massaroto (2008), desde que a noção de "estilo de vida” passou a ser uma variável sociológica determinante para o entendimento das relações sociais - tendo este processo se iniciado nas décadas de 1950 e 1960 - há, na cadeia produtiva das mais variadas indústrias, a preocupação com fatores que vão além da mera funcionalidade do produto. A necessidade, desde então, confunde-se com os desejos e os consumidores não apenas adquirem bens que realizem alguma tarefa de forma eficiente, mas querem, aliado à funcionalidade, um estilo que reforce sua personalidade e a imagem como gostariam de ser vistos. Estes fatores, enquanto fortes influências ao aumento do consumo vão de encontro a um dos grandes princípios defendidos pelos pesquisadores do tema sustentabilidade: o de que um consumo exagerado e sem controle gera um aumento de descarte e de resíduos, culminando nos mais diversos problemas ambientais (Leff 2008; Bacha et al. 2010).

O presente estudo justifica-se, portanto, por abordar uma atividade que tem presença forte em diversos municípios do Agreste pernambucano, sendo as economias de algumas cidades dependentes da indústria têxtil para que haja emprego e renda para a população. Propõe-se com esta pesquisa utilizar como referência o Índice de Desempenho da Gestão Ambiental para subsidiar o diagnóstico das práticas de indústrias do setor têxtil em Toritama, Pernambuco. Pretende-se contribuir para uma mudança de paradigmas no intuito de demonstrar aos produtores que o conhecimento do nível de maturidade da gestão ambiental da organização é um ponto de partida para o pleno conhecimento dos aspectos socioambientais relacionados ao empreendimento. 
O desempenho ambiental de uma instituição está relacionado ao controle que esta exerce sobre seus aspectos ambientais, e pode ser mensurado por meio da comparação dos resultados esperados das políticas ambientais da empresa com seus resultados práticos. Ou seja, esta análise pode fazer parte de uma ferramenta de gestão, já que tem foco em comparar o desempenho esperado com o observado.

A mensuração de desempenho é uma atividade constante e necessária no contexto amplo da gestão, seja esta financeira, de comunicação, produção, marketing, de pessoas ou a ambiental. O termo desempenho, portanto, pode ser definido como a informação quantificada do resultado obtido em processos, que pode ser comparada com algum padrão ou meta esperados (Luz et al. 2006).

Há diversas formas de se mensurar o desempenho ambiental de determinado empreendimento, sendo que a mais adequada depende do contexto em que está sendo aplicada. Há, por exemplo, uma metodologia de avaliação de desempenho ambiental de bacias hidrográficas desenvolvida pela United Nation Educational, Scientific and Cultural Organization (UNESCO) com base na análise de diversos indicadores que permitem definir, em termos numéricos, o estado atual da organização em termos ambientais, bem como permitem sugestões de melhorias. O World Resources Institute, por sua vez, tem um modelo mais generalista, adequado à análise de territórios e de setores econômicos, explorando quatro fatores: poluição ambiental, diminuição de recursos naturais, riscos ecossistêmicos e reflexos no bem-estar humano (Luz et al. 2006).

Para efeito deste estudo, o desempenho ambiental das empresas selecionadas foi classificado por meio da aplicação dos conceitos do Índice de Desenvolvimento da Gestão Ambiental (IDGA).

\section{Índice de Desempenho da Gestão Ambiental (IDGA)}

O Índice de Desempenho da Gestão Ambiental, indicador criado no âmbito do Programa de Desenvolvimento e Meio Ambiente da Universidade Federal de Pernambuco (PRODEMA/UFPE), tem a proposta de medir e classificar o nível de desenvolvimento da gestão ambiental de uma organização, funcionando como um indicador de desempenho ambiental baseado na ISO 14001 (Rede de defesa ambiental 2010).

Para a obtenção do IDGA de uma organização, seis fatores fundamentais relacionados a processos de produtividade, prevenção e controle são avaliados, sendo eles: Produtividade, prevenção para a comunidade, prevenção para formalização, prevenção para o crescimento, cadeia de prevenção e cadeia de controle. Estes fatores fundamentais são compostos de 17 elementos de avaliação que permitem o cálculo do nível de desenvolvimento da gestão ambiental, que pode variar de zero a 1 e possui escala de cinco categorias: muito baixo, baixo, médio, alto e muito alto. O detalhamento da aplicação do IDGA pode ser consultado na seção de Procedimentos Metodológicos deste documento (Selva e Barros 2014).

Contextos diversos são propícios à aplicação do IDGA. Desde empresas que pretendem ou estão em processo de desenvolvimento de um sistema de gestão ambiental, até aquelas que já o possuem, servindo como instrumento orientador de autoavaliação. Além disso, é possível, por meio do índice, estabelecer e acompanhar metas de desempenho ambiental, identificar fatores críticos para a melhoria do desempenho ambiental da instituição e um entendimento holístico de suas limitações e potencialidades ambientais

\section{Empreendimentos familiares}

Os negócios familiares são o tipo predominante de empresas em todo o mundo. É muito comum que empreendimentos iniciem-se com ideias, empenho e investimento de indivíduos e seus parentes. A história da 
economia brasileira, por exemplo, está marcada pela ampla presença de empresas familiares. Porém, a gestão de organizações desta categoria tem características bastante peculiares, com aspectos tanto positivos quanto negativos (Ricca 2007).

Uma empresa de cunho familiar tende a ser impulsionada em diversas direções. É comum que membros da família com poder de decisão no empreendimento possuam interesses conflitantes e, por ambos possuírem um sentimento de pertencimento em relação ao negócio, torna-se difícil a tomada de decisão racional. Outra característica importante deste tipo de empreendimento é o fato de valores e comportamentos da família afetarem políticas e decisões da empresa, o que tem reflexo nas carreiras, relacionamentos e finanças. Apesar disso, quando os dirigentes de um empreendimento são parentes, este consenso de valores pode facilitar a comunicação interna e favorece a confiança entre os tomadores de decisão, que têm fortes motivações pessoais para verem os negócios da empresa funcionando de forma lucrativa (Ricca 2007; Vries et al. 2008).

No caso das empresas familiares brasileiras, predomina um modelo de gestão patriarcal com poder absoluto e inquestionável dos proprietários, que passam o empreendimento a seus herdeiros e têm dificuldade em lidar com a descentralização e a delegação de tarefas importantes (Nogueira 2012).

As duas empresas em que foi realizado este trabalho têm estilo de gestão familiar e têm o empreendedor como principal tomador de decisões. Outros membros da família trabalham nas companhias e estão sendo orientados a respeito do mercado e das atividades da organização, o que dá a entender que o processo sucessório se dará dentro da família. A particularidade do pertencimento da família ao negócio é presente na maioria das empresas do interior do estado pernambucano e deve ser considerada quando das definições de estratégias empresariais.

\section{Indústria têxtil}

A responsabilidade socioambiental é premissa básica para qualquer atividade humana, principalmente para as potencialmente poluidoras, como a indústria têxtil, visto o alto consumo de água e à geração de efluentes com elevada carga orgânica.

Apesar deste alto potencial de geração de passivos ambientais, seus produtos apresentam alto consumo por se enquadrarem em artigos essenciais (peças de roupas, acessórios e sapatos, cama, mesa, banho) ao dia-a-dia das pessoas (Anicet et al. 2011).

\section{Lavanderias industriais}

Um dos nichos componentes do setor têxtil são as lavanderias industriais, que tratam-se de fábricas especializadas no beneficiamento de tecidos. Entende-se por beneficiamento os procedimentos após a tecelagem com o intento de alterar a aparência ou textura do tecido visando agregar valor. Uma lavanderia têxtil industrial, portanto, trabalha as peças de forma a gerar uma maior identidade no produto, tornando-o parte de tendências de moda e aumentando, assim, o interesse do consumidor pela peça final. Pode-se dizer que uma lavanderia é uma empresa especialista em acabamento de jeans e outros tecidos de estrutura semelhante, como o brim (Polli 2013; Brito 2013).

Nem sempre, contudo, o foco principal das lavanderias foi estético, já que este modelo de negócios surgiu antes da década de 1980, com a necessidade de retirar a goma que deixava o jeans com textura pouco flexível e pouco confortável. Ao longo dos anos, por influência da indústria da moda, foram sendo desenvolvidos métodos para influenciar também a estética do tecido, diferenciando as peças.De forma geral, as lavanderias industriais possuem processos produtivos bastante variáveis, que dependem do efeito que se pretende dar à peça beneficiada. Os inputs do processo são as peças de roupa costuradas em tecido cru, e os outputs são o produto final, pronto a ser vendido 
no atacado ou no varejo. O que ocorre entre estas duas etapas é definido de acordo com o efeito esperado da peça, portanto, pode ser uma lavagem simples intencionando apenas melhorar a textura do tecido e seu conforto, ou pode ser mais complexo, envolvendo tintas, desgaste físico no tecido e grandes quantidades de água.

Uma forma comum de simular o desbotamento do jeans envolve pedra pome, argila expandida, cloro e peróxido de hidrogênio. Em geral, o efeito de desgaste físico é conseguido por meio de lixas, jateamento de areia e outras formas de atrito, enquanto o desgaste químico demanda lavagens com alvejantes, enzimas e outros produtos químicos (Polli 2013; Brito 2013).

Os efluentes provenientes desses processos deveriam passar por tratamentos físico-químicos seguidos pelo tratamento biológico antes de serem descartados nos cursos d'água. O tratamento adequado dependerá da característica do efluente, porém, entre os métodos de tratamento mais modernos estão a degradação química dos compostos orgânicos por meio de reagentes oxidantes, tratamentos por reações fotoquímicas e tratamentos físicos por micro e nanofiltração (Polli 2013).

As operações de beneficiamento de tecidos descritas nesse tópico utilizam uma quantidade considerável de água e produtos químicos que devem ser adequadamente manipulados para que se minimizem os impactos ambientais, porém, poucas lavanderias têxteis dispõem de um sistema de gestão ambiental. Os efluentes oriundos do processo produtivo das lavanderias têxteis costumam ter $\mathrm{pH}$ elevado e coloração acentuada, o que denota elevada carga orgânica e toxicidade. E, no processo de tratamento para posterior descarte do efluente, é gerada grande quantidade de lodo com metais pesados e outros componentes tóxicos (Twardokus 2004).

\section{Material e MÉtodos}

Este estudo foi realizado em duas lavanderias de jeans localizadas no município de Toritama - Pernambuco (Figura 1). As atividades de lavanderia e tinturaria, dentro da cadeia produtiva têxtil, figuram como grande consumidoras de água, e este é um recurso escasso no Agreste pernambucano, região onde se localiza Toritama. Estas questões justificam um esforço no sentido de tornar mais sustentável o processo produtivo das empresas da região.

Figura 1. A) Vista aérea do município de Toritama, estado de Pernambuco, onde ficam localizadas as Lavanderias B) Céu Azul e C) Mamute. Fonte: Googleearth, 2018 (A e C). Autoria: Marília |Regina Costa Castro Lyra (B)

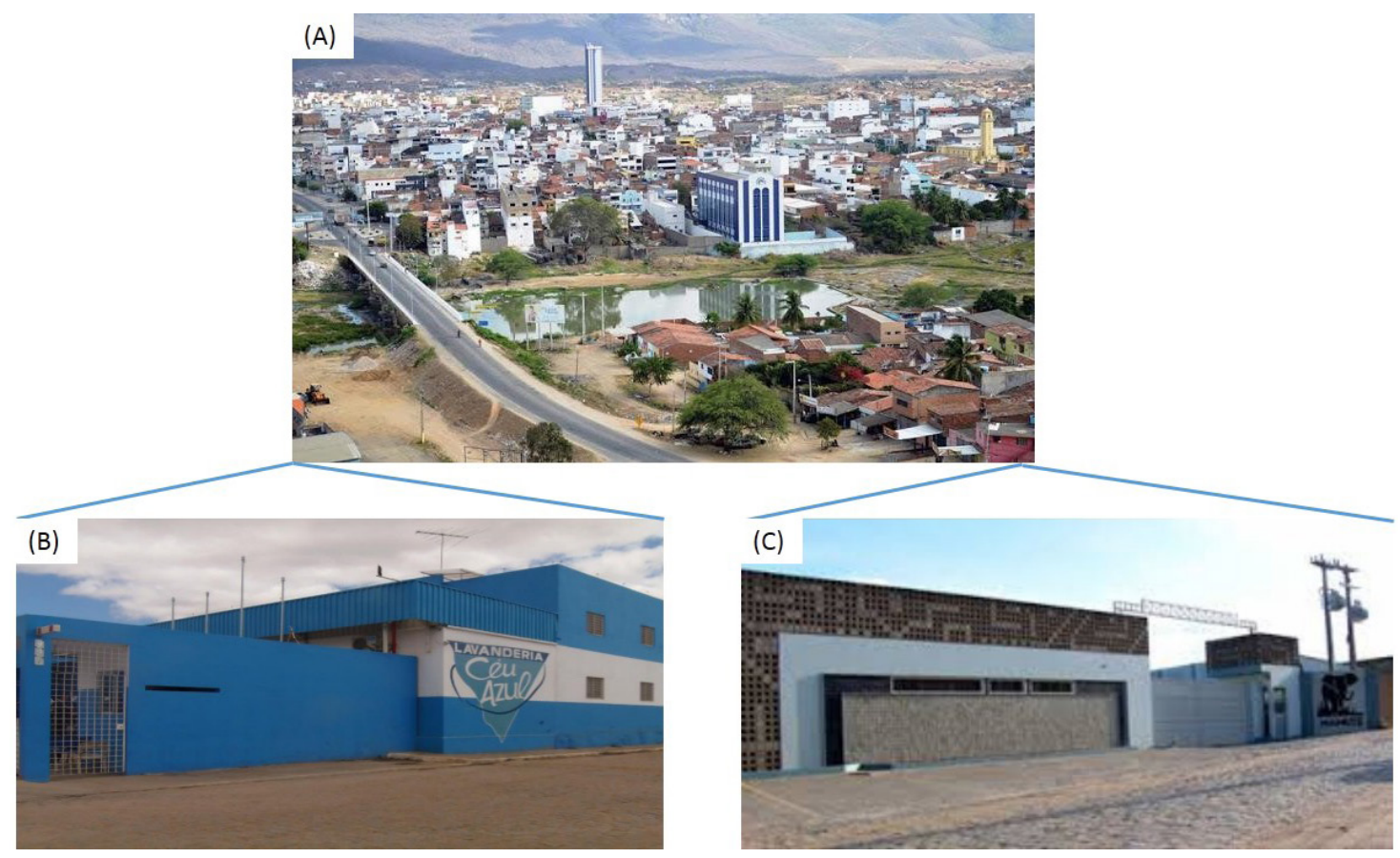


A Lavanderia Céu Azul é uma empresa de pequeno porte com administração de estilo familiar localizada no município de Toritama - PE. É uma das principais empresas do setor na região, fazendo parte de um grupo empresarial que dispõe, ainda, de uma marca própria de jeans com bom nível de penetração no mercado local.

Realiza as atividades de lavagem, estonagem (processo de lavagem que deixa o jeans com aspecto de usado ou envelhecido) e diversos outros tipos de beneficiamento do jeans. Sua produção vai de 5.000 a 7.000 peças por dia, realizada por 78 funcionários, todos homens. Para este volume de produção a empresa conta com 11 máquinas de lavar, 3 centrífugas e 6 secadoras, além de duas caldeiras que geram energia térmica por meio da queima de madeira algaroba - autorizada pelo IBAMA, conforme observar-se na Figura 2.

Figura 2. Atividades executadas no processo de Lavagem de Jeans na Lavanderia Céu Azul - localizada no Pólo Têxtil da cidade de Toritama - Pernambuco. A) Máquinas de lavagem do jeans; B) Máquina centrífuga; C) Máquinas secadoras para secagem das peças de jeans; D) Casa de Caldeiras para geração de vapor e energia. Autoria: Marilia Regina Costa Castro Lyra.

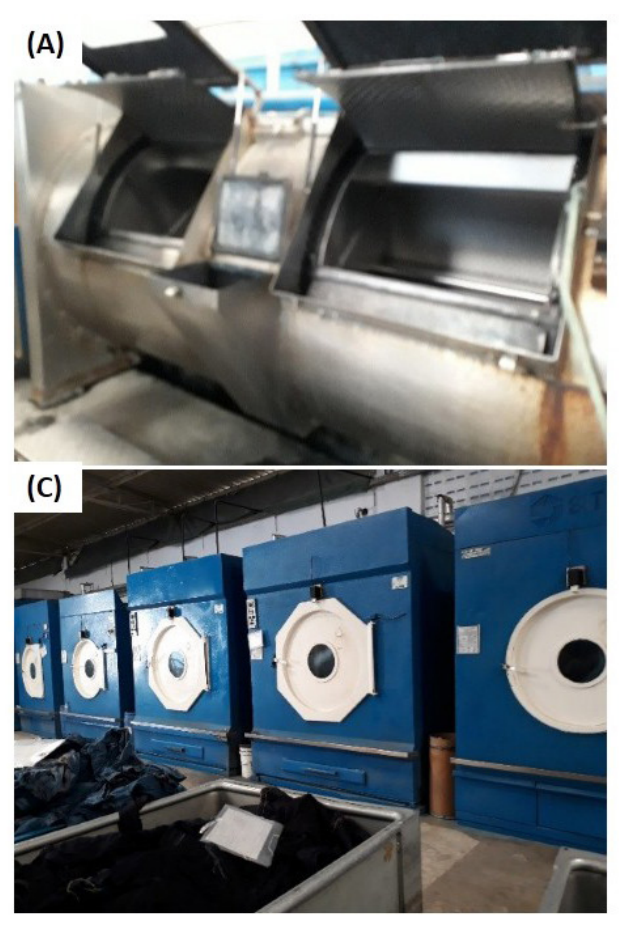

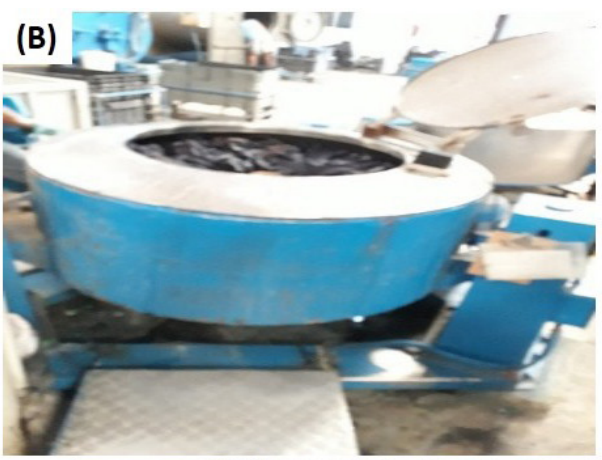

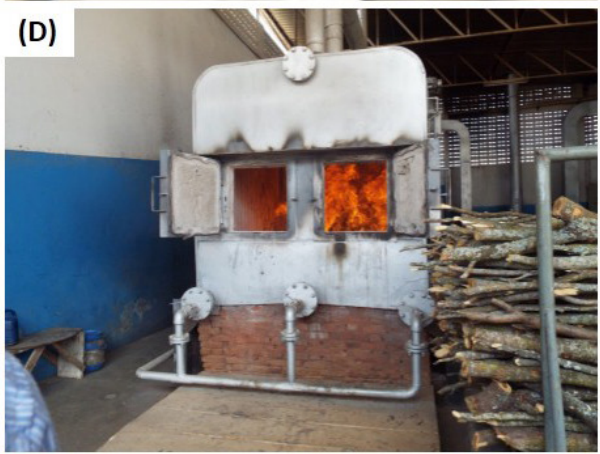

A água utilizada no processo produtivo é comprada de carros pipa, proveniente do Rio Capibaribe, porém, desde 2005, por recomendação do CPRH e do Ministério Público, a empresa possui uma estação de tratamento de efluentes, conseguindo, assim, reaproveitar entre $80 \%$ e $85 \%$ do recurso na época de estiagem e cerca de $50 \%$ no período chuvoso, porém, estão sendo estudados projetos que permitam o reaproveitamento de $100 \%$ da água. São geradas, com o processo produtivo e com o tratamento de efluentes, 10 toneladas de resíduos sólidos, que são entregues a uma empresa terceirizada mediante pagamento por tonelada e manipulados para reuso como tijolos ecológicos.

A empresa não dispõe de um sistema formal de gerenciamento ambiental, trabalhando com ações de controle para aspectos e impactos ambientais e implementando melhorias em seu processo à medida em que surge a necessidade. 
Localizada às margens do Rio Capibaribe, a Lavanderia Mamute é uma empresa de pequeno porte de administração familiar. Trata-se de uma das maiores lavanderias têxteis do agreste pernambucano, contando com empresas varejistas de grande porte em sua carteira de clientes, cujo nível de exigência quanto a padrões ambientais é elevado.

São utilizados 300 mil litros de água em cada um de seus três turnos diários (6h - 14h; $14 \mathrm{~h}-22 \mathrm{~h} ; 22 \mathrm{~h}-6 \mathrm{~h}$ ). Sua estação de tratamento de efluentes, no entanto, consegue o reaproveitamento de $85 \%$ a $95 \%$ do recurso. A Mamute foi a primeira lavanderia industrial de Toritama a implantar uma estação de tratamento de efluentes.

Assim como a Céu Azul, a Lavanderia Mamute utiliza a energia térmica advinda da queima de madeira algaroba licenciada pelo IBAMA em complemento à energia elétrica. Seus resíduos sólidos são destinados para um aterro localizado em Igarassu. Quanto ao maquinário, há 9 máquinas de lavar, 3 centrífugas e 5 secadoras.

A Mamute não dispõe de um sistema de gestão ambiental implementado, porém, atende a clientes com exigências elevadas quanto a padrões ambientais, o que impulsiona seu padrão de eficiência na utilização de recursos e no tratamento de efluentes.

\section{Procedimentos metodológicos}

O procedimento adotado para o cumprimento do objetivo geral da pesquisa é a pesquisa-ação, que preconiza a investigação de uma situação-problema seguida de uma tentativa continuada, sistemática e empiricamente fundamentada de aprimorar a prática - neste caso a necessidade de definição do nível de maturidade da gestão ambiental das organizações estudadas (Tripp 2005).

Foram realizadas visitas técnicas, entrevistas, pesquisa bibliográfica e documental. As pesquisas bibliográficas e documentais, que permitem ao investigador coleta de dados secundários para compreensão do fenômeno estudado (Gil 2002), têm relevância para que se conheçam os normativos pertinentes à atividade das empresas estudadas e os indicadores de mensuração de seu desempenho ambiental. As visitas técnicas e entrevistas, por sua vez, permitem a observação da realidade e sua comparação com os resultados esperados.

As pesquisas tiveram o intento principal de identificar, na literatura, exemplos de empresas que utilizaram com sucesso técnicas de reuso da água, descontaminação de resíduos ou mesmo que conseguiram mensurar o impacto que não é possível reduzir, realizando medidas compensatórias às atividades potencialmente degradantes ao ambiente natural. Após esta primeira análise, as entrevistas com os proprietários-dirigentes das empresas objeto deste estudo e com funcionários do setor de tratamento de efluentes permitiram o efetivo conhecimento do processo produtivo atual e dos pontos críticos de impacto no meio ambiente, além dos anseios da empresa quanto às melhorias pretendidas nos aspectos ambientais, bem como, na ocasião, foi definido o Índice de Desenvolvimento da Gestão Ambiental.

\section{Definição do Índice de Desenvolvimento da Gestão Ambiental}

Para determinar o grau de desempenho das empresas estudadas do ponto de vista da sustentabilidade de seus processos, foi utilizado o indicador quantitativo IDGA - Índice de Desenvolvimento da Gestão Ambiental, desenvolvido no âmbito do Programa de Pós-Graduação em Desenvolvimento e Meio Ambiente (PRODEMA/ UFPE). O Índice de Desenvolvimento da Gestão Ambiental é um indicador que mede e classifica o nível de desenvolvimento da gestão ambiental de uma organização (Barros et al. 2011). 
O cálculo do IDGA está atrelado à avaliação quantitativa de seis fatores - proatividade, prevenção para a comunidade, prevenção para formalização, prevenção para o crescimento, cadeia de prevenção e cadeia de controle - considerados fundamentais para o bom desempenho da gestão ambiental numa organização. Cada um dos fatores é subdividido em Índices de Implementação que fundamentam o cálculo do IDGA.

A média aritmética dos Índices de Implementação - que assumem uma das qualificações listadas na Tabela 1 - de cada fator analisado resulta no IDGA da organização. O cálculo dos Índices de Implementação foi realizado mediante a aplicação da fórmula abaixo:

$$
\mathrm{Ii}=\sum \mathrm{ni} / \mathrm{N} \rightarrow(\mathrm{ni} 1+\mathrm{ni} 2+\mathrm{ni} 3+\ldots \mathrm{nin}) / \mathrm{Nn}
$$

Onde:

Ii é o Índice de Implementação do fator analisado

ni é o valor atribuído ao nível de implementação observado em cada elemento dentro do fator analisado

$\mathbf{N}$ é a quantidade de elementos analisados dentro do fator

O IDGA da organização como um todo, portanto, é calculado por meio da média aritmética dos Índices de Implementação dos fatores:

IDGA org $=\sum \mathrm{Ii} / 6$ (número total de fatores analisados)

Tabela 1. Valores do ni e qualificação correspondente do IDGA

\begin{tabular}{|c|c|c|}
\hline Valores do ni & $\begin{array}{l}\text { Qualificação do nível } \\
\text { de implementação }\end{array}$ & Descrição do nível \\
\hline 1 & Avançado & $\begin{array}{l}\text { Efetividade consolidada e processos permanentes de melhoria contínua e } \\
\text { aperfeiçoamento. }\end{array}$ \\
\hline 0,8 & Substancial & $\begin{array}{l}\text { O primeiro ciclo de implementação já foi cumprido e há informações e } \\
\text { resultados substanciais }\end{array}$ \\
\hline 0,6 & Intermediário & $\begin{array}{l}\text { Fase de implementação, porém o primeiro ciclo do PDCA ainda não foi } \\
\text { concluído }\end{array}$ \\
\hline 0,4 & Básico & Há um planejamento formal e uma estrutura básica para sua implementação \\
\hline 0,2 & Inicial & $\begin{array}{l}\text { Embora ainda não haja planejamento formal, algumas decisões ou medidas } \\
\text { administrativas vêm sendo adotadas }\end{array}$ \\
\hline 0 & Inexistente & O elemento inexiste/foi suspenso ou cancelado \\
\hline
\end{tabular}

Fonte: Barros et al (2011).

$\mathrm{Na}$ Tabela 2 estão disponíveis as pontuações às quais estão relacionadas as categorias de qualificação. Com o intuito de permitir uma comparação de análises, neste estudo, o IDGA das companhias foi definido por meio de avaliações realizadas por um auditor interno - representado por um dirigente da companhia avaliada - e, como forma de comparação e teste da metodologia, a autora deste documento realizou o papel de auditora externa. O questionário foi respondido pelo auditor interno e pela auditora externa, gerando dois índices para cada empresa. 
Tabela 2. Níveis de desenvolvimento da gestão ambiental

\begin{tabular}{cc}
\hline Escala do IDGA & Categorias \\
\hline 0 a 0,2 & Muito Baixo \\
0,21 a 0,4 & Baixo \\
0,41 a 0,6 & Médio \\
0,61 a 0,8 & Alto \\
0,81 a 1 & Muito alto \\
\hline
\end{tabular}

Fonte: Barros et al (2011).

\section{RESUltados E Discussão}

O Quadro 1 apresenta o detalhamento do cálculo do IDGA da Lavanderia Céu Azul conforme as análises dos auditores interno - representado por funcionário do setor de tratamento de efluentes - e externo - representado pela autora deste documento -, respectivamente.

Quadro 1. Tabulação e cálculo do IDGA da Lavanderia Céu Azul pela análise dos auditores interno e externo.

\begin{tabular}{|c|c|c|c|c|c|}
\hline \multirow[b]{2}{*}{ Fator } & \multirow[b]{2}{*}{ Elementos } & \multicolumn{2}{|c|}{ Auditor interno } & \multicolumn{2}{|c|}{ Auditor externo } \\
\hline & & $\begin{array}{c}\text { Nível de } \\
\text { Implementação }\end{array}$ & $\mathrm{Ni}$ & $\begin{array}{c}\text { Nível de } \\
\text { Implementação }\end{array}$ & $\mathrm{Ni}$ \\
\hline \multirow{6}{*}{ 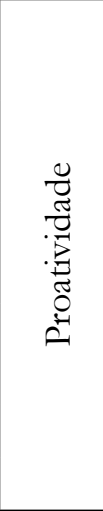 } & $\begin{array}{l}\text { A organização possui autoridade formal designada por } \\
\text { função específica para a gestão ambiental }\end{array}$ & Avançado & 1 & Básico & 0,4 \\
\hline & $\begin{array}{l}\text { Os objetivos ambientais fazem parte da formulação das } \\
\text { estratégias de negócio da organização }\end{array}$ & Substancial & 0,8 & Intermediário & 0,6 \\
\hline & $\begin{array}{l}\text { A organização possui programa permanente de educação } \\
\text { ambiental }\end{array}$ & Inexistente & 0 & Inicial & 0,2 \\
\hline & $\begin{array}{l}\text { A organização possui programa permanente de } \mathrm{P} \& \mathrm{D} \text { em } \\
\text { tecnologias limpas ou ecoeficientes }\end{array}$ & Inicial & 0,2 & Inicial & 0,2 \\
\hline & $\sum$ ni & \multicolumn{2}{|l|}{2} & \multicolumn{2}{|l|}{1,4} \\
\hline & $\mathrm{Ii}=\sum \mathrm{ni} / 4$ & \multicolumn{2}{|l|}{0,5} & \multicolumn{2}{|l|}{0,35} \\
\hline \multirow{5}{*}{ 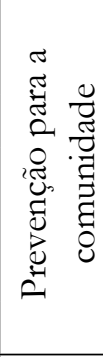 } & $\begin{array}{l}\text { A organização possui mecanismo institucional de canal de } \\
\text { comunicação com a comunidade }\end{array}$ & Básico & 0,4 & Inicial & 0,2 \\
\hline & A organização possui quadro de especialistas ambientais & Inicial & 0,2 & Inicial & 0,2 \\
\hline & $\begin{array}{l}\text { A organização realiza ações conjuntas de co-gestão de riscos } \\
\text { ambientais com a comunidade }\end{array}$ & Inexistente & 0 & Inexistente & 0 \\
\hline & $\sum \mathrm{ni}$ & \multicolumn{2}{|l|}{0,6} & \multicolumn{2}{|l|}{0,4} \\
\hline & $\mathrm{Ii}=\sum \mathrm{ni} / 3$ & \multicolumn{2}{|l|}{0,2} & \multicolumn{2}{|l|}{0,13} \\
\hline \multirow{4}{*}{ 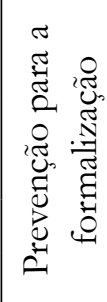 } & $\begin{array}{l}\text { A organização adota realização de auditorias ambientais } \\
\text { periódicas }\end{array}$ & Avançado & 1 & Substancial & 0,8 \\
\hline & $\begin{array}{l}\text { A organização adota eventos formais como a elaboração e } \\
\text { publicação de relatórios ambientais }\end{array}$ & Substancial & 0,8 & Intermediário & 0,6 \\
\hline & $\sum \mathrm{ni}$ & \multicolumn{2}{|l|}{1,8} & \multicolumn{2}{|l|}{1,4} \\
\hline & $\mathrm{Ii}=\sum \mathrm{ni} / 3$ & \multicolumn{2}{|l|}{0,9} & \multicolumn{2}{|l|}{0,7} \\
\hline
\end{tabular}




\begin{tabular}{|c|c|c|c|c|c|}
\hline \multirow{5}{*}{ 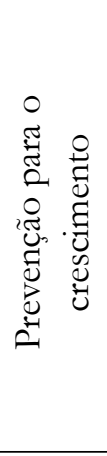 } & $\begin{array}{l}\text { A organização pesquisa a opinião dos consumidores para } \\
\text { melhorar sua postura ou sistema de gestão ambiental }\end{array}$ & Intermediário & 0,6 & Intermediário & 0,6 \\
\hline & $\begin{array}{l}\text { A organização adota inovações tecnológicas para o uso } \\
\text { sustentável de recursos naturais e mitigação de impactos } \\
\text { ambientais }\end{array}$ & Substancial & 0,8 & Intermediário & 0,6 \\
\hline & $\begin{array}{l}\text { A organização prevê orçamento próprio para o } \\
\text { desenvolvimento da gestão ambiental }\end{array}$ & Inexistente & 0 & Inicial & 0,2 \\
\hline & & $\sum \mathrm{ni}$ & 1,4 & $\sum \mathrm{ni}$ & 1,4 \\
\hline & & $\mathrm{Ii}=\sum \mathrm{ni} / 3$ & 0,47 & $\mathrm{Ii}=\sum \mathrm{ni} / 3$ & 0,47 \\
\hline \multirow{4}{*}{ 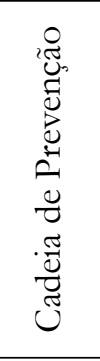 } & $\begin{array}{l}\text { A organização faz exigências aos seus fornecedores quanto a } \\
\text { aspectos ambientais }\end{array}$ & Inicial & 0,2 & Inicial & 0,2 \\
\hline & $\begin{array}{l}\text { A organização internamente divulga as suas ações de gestão } \\
\text { ambiental e lições aprendidas para reproduzir as melhores } \\
\text { práticas ambientais }\end{array}$ & Básico & 0,4 & Básico & 0,4 \\
\hline & & $\sum \mathrm{ni}$ & 0,6 & $\sum \mathrm{ni}$ & 0,6 \\
\hline & & $\mathrm{Ii}=\sum \mathrm{ni} / 2$ & 0,3 & $\mathrm{Ii}=\sum \mathrm{ni} / 2$ & 0,3 \\
\hline \multirow{5}{*}{ 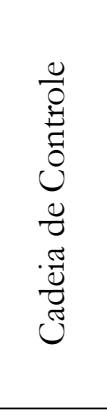 } & $\begin{array}{l}\text { A organização exerce controle dos níveis da gestão ambiental } \\
\text { através da medição dos níveis de poluição }\end{array}$ & Básico & 0,4 & Intermediário & 0,6 \\
\hline & $\begin{array}{l}\text { A organização cumpre a legislação e requisitos legais } \\
\text { ambientais }\end{array}$ & Substancial & 0,8 & Substancial & 0,8 \\
\hline & $\begin{array}{l}\text { A organização aplica tecnologias que tratam os resíduos e } \\
\text { efluentes no final do processo produtivo }\end{array}$ & Substancial & 0,8 & Intermediário & 0,6 \\
\hline & $\sum$ ni & \multicolumn{2}{|l|}{2} & \multicolumn{2}{|l|}{2} \\
\hline & $\mathrm{Ii}=\sum \mathrm{ni} / 3$ & \multicolumn{2}{|l|}{0,67} & \multicolumn{2}{|l|}{0,67} \\
\hline & $\sum \mathrm{Ii}$ & \multicolumn{2}{|l|}{3,04} & \multicolumn{2}{|l|}{2,62} \\
\hline & IDGAorg $=\sum$ Ii $/ 6$ & \multicolumn{2}{|l|}{0,51} & \multicolumn{2}{|l|}{0,43} \\
\hline
\end{tabular}

De acordo com as análises do auditor interno e do auditor externo, a Lavanderia Céu Azul está na categoria de nível médio no que tange ao desenvolvimento da gestão ambiental. É possível perceber, com a observação das análises qualitativas dos fatores que compõem a definição do IDGA, que a empresa demonstra não apenas uma boa vontade quanto à melhoria constante dos processos relacionados à gestão ambiental, mas também implementa tecnologias que se provem mais eficientes ou menos agressivas ao meio ambiente.

Nesta perspectiva, Ribeiro e Tavares (2018) destacam que os principais impactos ambientais gerados na indústria têxtil estão vinculados ao consumo de água, principal matéria-prima empregada na atividade, e a produção de efluentes líquidos e resíduos sólidos com elevada carga orgânica, agentes químicos tóxicos e corantes. Neste cenário, enfatizam que a indústria têxtil necessita adotar práticas e tecnologias que visem a redução dos impactos provocados no ambiente, principalmente relacionados a minimização da quantidade de água potável empregada em seus processos e o tratamento adequado dos efluentes e resíduos, para remoção dos agentes contaminantes, antes do seu descarte no meio ambiente.

Os fatores, Proatividade (Item: a organização possui programa permanente de P\&D em tecnologias limpas ou ecoeficientes), Prevenção para o crescimento (Item: a organização adota inovações tecnológicas para o uso sustentável de recursos naturais e mitigação de impactos ambientais) e Cadeia de Controle (Itens: a organização cumpre a legislação e requisitos legais ambientais e a organização aplica tecnologias que tratam os resíduos e efluentes no final do processo produtivo) que fazem parte da composição do IDGA e correlacionam-se a mitigação destes impactos, para as Lavanderias em análise, evidenciam uma evolução quanto a responsabilidade socioambiental das organizações, visto terem alcançado os status intermediários e substanciais.

O que se demonstra é o entendimento de que seguir as leis ambientais torna-se mais natural à empresa quando a cultura da economia de água e de insumos, da melhoria dos processos de tratamento de efluentes e do 
descarte adequado de resíduos se torna vigente no estilo de gestão. O planejamento da organização como um todo considera a gestão ambiental uma forma de obter efetivos ganhos financeiros por meio de processos que utilizam menor quantidade de água e de produtos químicos nos processos de tingimento, sobrecarregando menos, assim, o sistema de tratamento de efluentes e gerando economia nos insumos, além de prevenir autuações por não conformidades nos processos.

Entretanto, Cometti et al. (2016), em diagnóstico ambiental das lavanderias de jeans de Toritama-PE, realizado no período de 2014 e 2015, abordando indicadores ambientais que geram impactos sob o solo, ar, recursos hídricos e biodiversidade, verificaram que esta não é a realidade da maior parte das Lavanderias do município, visto que apenas 50 das empresas licenciadas a época atendiam aos requisitos ambientais de controle ambiental, como estação de tratamento de efluentes e sistema de controle de emissões atmosféricas. Não obstante, boa parte delas já foram autuadas pela CPRH por descumprimento de obrigações legais e lançamento de efluente sem tratamento no rio Capibaribe.

Aponta ainda, uma redução do número destes empreendimentos em operação no município em 2016, creditando a ação punitiva por parte dos órgãos fiscalizadores, pelo aumento significativo no número de autuações por lançamento de efluente fora dos padrões ambientais, desobediência às exigências de licenças e ausência de licenciamento ambiental. Porém, no que se refere à destinação dos resíduos sólidos industriais, a pesquisa indicou um considerável avanço na destinação adequada, desafogando o lixão municipal, creditando as mudanças também ao monitoramento, ações educativas, oficinas de licenciamento ambiental, workshops e audiências públicas realizadas no município pelo órgão ambiental.

O questionário para cálculo do IDGA também foi respondido pelo funcionário responsável pela estação de tratamento de efluentes da Lavanderia Mamute na qualidade de auditor interno, e o papel de auditor externo foi novamente assumido pela autora deste documento. O Quadro 2 apresenta o detalhamento do cálculo do IDGA da Lavanderia Mamute.

As análises dos auditores interno e externo tiveram como resultado do IDGA o nível médio, embora tenha havido alguma diferença quanto à pontuação final. A Lavanderia Mamute demonstra algum nível de entendimento quanto a todos os fatores e subfatores abordados no índice, alguns em maior - como o fato de já adotar funções responsáveis pela gestão ambiental no organograma - e outros em menor grau - como a comunicação com a comunidade, que ainda não tem sido formalizada. De forma semelhante à Lavanderia Céu Azul, o interesse pela gestão ambiental iniciou quando ficou clara a possibilidade de a Mamute obter ganhos de eficiência enquanto cumpria as demandas legais. Atualmente, faz parte da cultura da empresa buscar e implementar soluções que melhorem o desempenho ambiental e de maior tecnologia a agregar aos processos.

Quadro 2. Tabulação e cálculo do IDGA da Lavanderia Mamute pelas análises dos auditores interno e externo.

\begin{tabular}{|c|c|c|c|c|c|}
\hline \multirow[b]{2}{*}{ Fator } & \multirow[b]{2}{*}{ Elementos } & \multicolumn{2}{|c|}{ Auditor interno } & \multicolumn{2}{|c|}{ Auditor interno } \\
\hline & & $\begin{array}{c}\text { Nível de } \\
\text { Implementação }\end{array}$ & $\mathrm{Ni}$ & $\begin{array}{c}\text { Nível de } \\
\text { Implementação }\end{array}$ & $\mathrm{Ni}$ \\
\hline \multirow{6}{*}{ 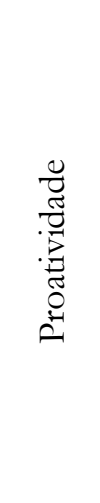 } & $\begin{array}{l}\text { A organização possui autoridade formal designada por função } \\
\text { específica para a gestão ambiental }\end{array}$ & Substancial & 0,8 & Intermediário & 0,6 \\
\hline & $\begin{array}{l}\text { Os objetivos ambientais fazem parte da formulação das } \\
\text { estratégias de negócio da organização }\end{array}$ & Intermediário & 0,6 & Básico & 0,4 \\
\hline & $\begin{array}{l}\text { A organização possui programa permanente de educação } \\
\text { ambiental }\end{array}$ & Básico & 0,4 & Inicial & 0,2 \\
\hline & $\begin{array}{l}\text { A organização possui programa permanente de P\&D em } \\
\text { tecnologias limpas ou ecoeficientes }\end{array}$ & Inicial & 0,2 & Inicial & 0,2 \\
\hline & $\sum$ ni & \multicolumn{2}{|l|}{2} & \multicolumn{2}{|l|}{1,4} \\
\hline & $\mathrm{Ii}=\sum \mathrm{ni} / 4$ & \multicolumn{2}{|l|}{0,5} & \multicolumn{2}{|l|}{0,35} \\
\hline
\end{tabular}




\begin{tabular}{|c|c|c|c|c|c|}
\hline \multirow{5}{*}{ 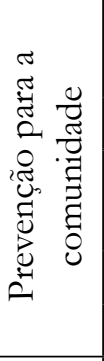 } & $\begin{array}{l}\text { A organização possui mecanismo institucional de canal de } \\
\text { comunicação com a comunidade }\end{array}$ & Básico & 0,4 & Inexistente & 0 \\
\hline & A organização possui quadro de especialistas ambientais & Intermediário & 0,6 & Intermediário & 0,6 \\
\hline & $\begin{array}{l}\text { A organização realiza ações conjuntas de co-gestão de riscos } \\
\text { ambientais com a comunidade }\end{array}$ & Inexistente & 0 & Inexistente & 0 \\
\hline & $\sum \mathrm{ni}$ & \multicolumn{2}{|l|}{1} & \multicolumn{2}{|l|}{0,6} \\
\hline & $\mathrm{Ii}=\sum \mathrm{ni} / 3$ & \multicolumn{2}{|l|}{0,33} & \multicolumn{2}{|l|}{0,2} \\
\hline \multirow{4}{*}{ 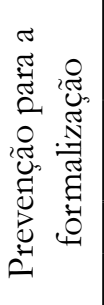 } & $\begin{array}{l}\text { A organização adota realização de auditorias ambientais } \\
\text { periódicas }\end{array}$ & Avançado & 1 & Substancial & 0,8 \\
\hline & $\begin{array}{l}\text { A organização adota eventos formais como a elaboração e } \\
\text { publicação de relatórios ambientais }\end{array}$ & Intermediário & 0,6 & Básico & 0,4 \\
\hline & $\sum \mathrm{ni}$ & \multicolumn{2}{|l|}{1,6} & \multicolumn{2}{|l|}{1,2} \\
\hline & $\mathrm{Ii}=\sum \mathrm{ni} / 2$ & \multicolumn{2}{|l|}{0,8} & \multicolumn{2}{|l|}{0,6} \\
\hline \multirow{5}{*}{ 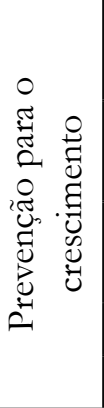 } & $\begin{array}{l}\text { A organização pesquisa a opinião dos consumidores para } \\
\text { melhorar sua postura ou sistema de gestão ambiental }\end{array}$ & Básico & 0,4 & Básico & 0,4 \\
\hline & $\begin{array}{l}\text { A organização adota inovações tecnológicas para o uso sustentável } \\
\text { de recursos naturais e mitigação de impactos ambientais }\end{array}$ & Substancial & 0,8 & Intermediário & 0,6 \\
\hline & $\begin{array}{l}\text { A organização prevê orçamento próprio para o desenvolvimento } \\
\text { da gestão ambiental }\end{array}$ & Intermediário & 0,6 & Básico & 0,4 \\
\hline & $\sum$ ni & \multicolumn{2}{|l|}{1,8} & \multicolumn{2}{|l|}{1,4} \\
\hline & $\mathrm{Ii}=\sum \mathrm{ni} / 3$ & \multicolumn{2}{|l|}{0,6} & \multicolumn{2}{|l|}{0,47} \\
\hline \multirow{4}{*}{ 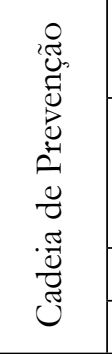 } & $\begin{array}{l}\text { A organização faz exigências aos seus fornecedores quanto a } \\
\text { aspectos ambientais }\end{array}$ & Básico & 0,4 & Substancial & 0,8 \\
\hline & $\begin{array}{l}\text { A organização internamente divulga as suas ações de gestão } \\
\text { ambiental e lições aprendidas para reproduzir as melhores } \\
\text { práticas ambientais }\end{array}$ & Substancial & 0,8 & Básico & 0,4 \\
\hline & $\sum \mathrm{ni}$ & \multicolumn{2}{|l|}{1,2} & \multicolumn{2}{|l|}{1,2} \\
\hline & Ii $=\sum$ ni $/ 2$ & \multicolumn{2}{|l|}{0,6} & \multicolumn{2}{|l|}{0,6} \\
\hline \multirow{5}{*}{$\begin{array}{l}\frac{0}{0} \\
0 \\
0 \\
0 \\
0 \\
0 \\
0 \\
. \frac{\pi}{0} \\
\frac{\tilde{U}}{\tilde{J}}\end{array}$} & $\begin{array}{l}\text { A organização exerce controle dos níveis da gestão ambiental } \\
\text { através da medição dos níveis de poluição }\end{array}$ & Intermediário & 0,6 & Básico & 0,4 \\
\hline & A organização cumpre a legislação e requisitos legais ambientais & Substancial & 0,8 & Intermediário & 0,6 \\
\hline & $\begin{array}{l}\text { A organização aplica tecnologias que tratam os resíduos e } \\
\text { efluentes no final do processo produtivo }\end{array}$ & Substancial & 0,8 & Intermediário & 0,6 \\
\hline & $\sum \mathrm{ni}$ & \multicolumn{2}{|l|}{2,2} & \multicolumn{2}{|l|}{1,6} \\
\hline & $\mathrm{Ii}=\sum \mathrm{ni} / 3$ & \multicolumn{2}{|l|}{0,73} & \multicolumn{2}{|l|}{0,53} \\
\hline & $\sum$ Ii & \multicolumn{2}{|l|}{3,56} & \multicolumn{2}{|l|}{2,55} \\
\hline & IDGAorg = & \multicolumn{2}{|l|}{0,59} & \multicolumn{2}{|l|}{0,42} \\
\hline
\end{tabular}

As duas empresas estudadas estão inseridas em um contexto de dificuldades sazonais de obtenção de água e num ambiente onde existem diversos empreendimentos de atividade semelhante atuando informalmente. Tratamse, portanto, de exemplos de organizações que optaram por atuar respeitando os normativos ambientais e por incluir princípios de gestão ambiental em sua política de gestão. Uma manutenção do curso decisório no caminho de aprimorar as práticas ambientais pode incrementar o resultado do IDGA das lavanderias, o que tem impacto positivo quanto ao estresse ambiental local. 


\section{Conclusão}

A problemática que orientou a construção do presente documento foi a dicotomia existente entre o crônico potencial de geração de externalidades negativas atrelado à atividade das lavanderias têxteis e a importância deste setor para a manutenção do desenvolvimento econômico dos municípios que fazem parte do polo de confecções do agreste pernambucano. Há mais de 100 mil empregos gerados na região, além de uma alta concentração de estabelecimentos comerciais têxteis.

O setor têxtil está inserido num mercado altamente dinâmico e competitivo, ao mesmo tempo em que é alvo de diversos normativos relacionados a seu potencial de geração de impactos ambientais negativos. Este trabalho, portanto, atuou de forma a mapear os principais pontos de melhoria referentes à gestão de duas lavanderias têxteis localizadas no município de Toritama, Pernambuco.

O mecanismo utilizado para mensurar o nível de desenvolvimento da gestão ambiental das empresas estudadas foi o IDGA, já que o indicador engloba a análise de diversos aspectos e, além de seu resultado final, o tomador de decisões pode observar cada um dos fatores avaliados e perceber onde deve concentrar seus principais esforços de melhoria.

Os resultados dos cálculos do IDGA da Lavanderia Céu Azul e da Lavanderia Mamute foram semelhantes, tendo como resultado o nível médio de desenvolvimento da gestão ambiental. As duas lavanderias estudadas possuem diversos pontos de semelhança entre si, e isto influenciou sua escolha para a realização deste estudo. Porém, a aplicação do IDGA e as visitas técnicas demonstraram nuances contextuais distintas, que demandam aplicações diferentes para que a melhoria do desempenho ambiental esteja atrelada a um bom custo x benefício para a companhia.

As empresas objeto deste estudo são referência no polo de confecções do Agreste pernambucano, tendo, inclusive, clientes em diversos estados do Brasil. O intuito deste trabalho é fomentar o desenvolvimento e consolidação das ações de responsabilidade socioambiental das empresas do setor têxtil, mantendo sua competitividade no mercado e seus resultados econômicos. É importante que este não seja um processo estanque, mas sim contínuo de aperfeiçoamento e melhorias. Dessa forma, não há impedimento para que, no longo prazo, as empresas do Agreste pernambucano tornem-se referência em práticas de gestão ambiental.

\section{REFERÊNCIAS}

ABIT. 2014. Perfil do setor têxtil e de confecção. Disponível em: <http://www.abit.org.br/Servicos.aspx\#43|SD|C>. Acesso em 11 ago 2014.

Anicet A, Bessa P, Broega AC. 2011. Ações na área da moda em busca de um design sustentável. In: Repositorium, Braga (Portugal). Anais eletrônicos. Braga: Universidade do Minho,1-8 Disponível em:<http://repositorium.sdum.uminho.pt/ bitstream/1822/14959/1/GT89897\%20A\%C3\%A7\%C3\%B5es\%20na\%20\%C3\%A1rea\%20da\%20moda\%20em\%20 busca $\% 20 \mathrm{de} \% 20$ um $\% 20$ design $\% 20$ sustent $\%$ C3\%A1vel.pdf>. Acesso em: 26 ago. 2014.

Bacha M L, Santos J, Schaun A. 2010. Considerações teóricas sobre o conceito de sustentabilidade. In: Simpósio de Excelência em Gestão e Tecnologia, 7, Resende. Anais. Resende/ RJ, SEGET.p. 289-300.

Barros AP. 2011. Índice de Desenvolvimento da Gestão Ambiental (IDGA): uma proposta de indicador de desempenho ambiental para as empresas de Suape. In: $13^{\circ}$ Congresso Nordestino de Ecologia.Anais. Recife, Sociedade Nordestina de Ecologia. p. 125-135. 
BellenHM.2005.Indicadoresdesustentabilidade:umaanálisecomparativa.CadernosEbape.br,RiodeJaneiro,v.3,n.3,Disponível em: < http://www.scielo.br/scielo.php?script=sci_pdf\&pid=S167939512005000300012\&lng=en\&nrm=iso\&tlng=pt>. Acesso em: 26 ago. 2014.

Brito GA. 2013. Sustentabilidade: um desafio para as lavanderias industriais. REDIGE, vol. 4 (2). 56-75.

Cometti JLS, Silva FL, Santos FJH, Lima VA. 2016. Diagnóstico ambiental comparativo entre 2014 e 2015 das indústrias têxteis (Lavanderia de jeans) do município de Toritama/PE. In: VII Congresso Brasileiro de Gestão Ambiental. Campina Grande/PB. p.1-6.

DIEESE. 2010. Relatório final: Diagnóstico do setor têxtil e de confecções de Caruaru e Região. Recife: DIEESE.76p.

Frank CS. 2004. Avaliação de fotorreatores na degradação de corantes reativos e efluente têxtil. Dissertação (Mestrado em Química). Universidade Federal de Santa Maria. Santa Maria, RS. 122p.

Gil AC. 2002. Como elaborar projetos de pesquisa. 4. ed. São Paulo: Atlas.176p.

Leff E. 2008. Saber ambiental: sustentabilidade, racionalidade, complexidade, poder. Petrópolis: Vozes,. 6 ed. 498p.

Luz SOC, Sellitto MA, Gomes LP. 2006. Medição de desempenho ambiental baseada em método multicriterial de apoio à decisão: estudo de caso na indústria automotiva. Revista Gestão e Produção, vol. 13 (3). 557-570.

Massaroto LP. 2008. Moda e identidade: o consumo simbólico do vestuário. In: Colóquio de moda, Novo Hamburgo. Anais. Novo Hamburgo, FEEVALE. 4:1-12.

Nogueira LSJ. 2012. Sucessão em empresas familiares: um estudo multicaso no Amazonas. Rio de janeiro: E-Papers.76p.

Polli A. 2013. Gerenciamento de impactos ambientais em lavanderias têxteis. Revista brasileira de gestão ambiental, vol. 7 (2), 12-18.

Rede de defesa ambiental. 2010. Projeto IDGA. 35p. Disponível em: <http://www.redeambiental.org/site/index. php?option=com_content\&view=article\&id=3:projetoidga\&catid=4:novidades $>$. Acesso em: 08 jan 2015.

Ribeiro VAS \& Tavares CRG. 2018. Analysis of reuse of jeans laundry effluent treated by heterogeneous photocatalysis. Brazilian Journal of Animal and Environmental Research, Curitiba, v. 1, n. 2, p. 395-404.

Ricca D. 2007. Sucessão na empresa familiar: Conflitos e soluções. São Paulo: Cla Editora.154p.

Santiago RS. 2011. Gestão ambiental na indústria têxtil: estudo de casos no Ceará. João Pessoa, PB: UFPB. Dissertação (Mestrado em Engenharia de Produção) - Universidade Federal da Paraíba, João Pessoa. 110 p.

Silva AN \& Almeida HA. 2017. Diagnostico do uso e reuso da água nas lavanderias têxtil de Toritama, Pernambuco. Anais. II Congresso Internacional da diversidade do Semiárido. p. 1-10.

SEBRAE. 2011. Indústria têxtil no Brasil.Disponível em: < http://www.sebrae.com.br/setor/textil-e-confeccoes/o-setor/ panorama/145-7-industria-textil-no-brasil/BIA_1457>. Acesso em: 9 mar 2014.

Selva VS F, Barros AP, Barros KAS. 2014. IDGA - Índice de Desenvolvimento da Gestão Ambiental: uma proposta de indicador de desempenho. Meio Ambiente Industrial, São Paulo, p.57 - 67. 
Tashizaua T, Andrade ROB. 2008. Gestão Socioambiental: estratégias na nova era da sustentabilidade. Rio de Janeiro: Elsevier. 250p.

Tenório JNB, Santos SM dos, Castro Júnior OV, Araújo FA de. 2006. A gestão ambiental e a competitividade na indústria têxtil. In: Congresso Internacional de Custos, 4, Braga, Portugal, Anais.p.389-384

Tripp D. 2005. Pesquisa-ação: uma introdução metodológica. Revista Educação e Pesquisa, vol 31 (3).443-466

Twardokus RG. 2004. Reuso de água no processo de tingimento da indústria têxtil. Dissertação (Mestrado em Engenharia Química) - Universidade Federal de Santa Catarina, Florianólpolis. 136 p.

Vries MFRK, Carlock RS, Florent-Treacy EF. 2008. A empresa familiar no divã: uma perspectiva psicológica. São Paulo: Bookman. 302p. 